\title{
Calcium Urolithiasis, Blood Pressure and Salt Intake
}

\author{
FRANCESCA TIMIO ${ }^{1}$, SALLY M. KERRY ${ }^{1}$, KEN M. ANSON ${ }^{2}$, JOHN B. EASTWOOD ${ }^{3}$ AND \\ FRANCESCO P. CAPPUCCIO ${ }^{1}$
}

From the ${ }^{1}$ Department of Community Health Sciences, St George's Hospital Medical School, ${ }^{2}$ Department of Urology, St George's Hospital Medical School, ${ }^{3}$ Department of Renal Medicine, St George's Hospital Medical School, London, UK

\section{Timio F, Kerry SM, Anson KM, Eastwood JB, Cappuccio FP. Calcium urolithiasis, blood pressure} and salt intake. Blood Pressure 2003; 12: 122-127.

Objectives: To determine whether stone-formers have higher BP than controls drawn from the general population and matched for age, sex and ethnic origin and to compare the relationship between sodium and calcium excretion in the two groups. Patients and methods: Thirty-six patients [mean ( \pm standard deviation, SD) $=49.0 \pm 11.7$ years; range $27-70$ years] with kidney or ureteric stones and 108 controls (mean age of $49.6 \pm 6.8$ years; range 39-61 years), matched for gender, ethnic origin and age group were studied. Patients and controls underwent physical measurements, a venous blood sample and they were asked to collect a 24-h urine sample for sodium, potassium, calcium and creatinine. Results: Stoneformers were significantly heavier and had higher BP than age-, sex- and ethnic-matched population controls. Whilst the difference in systolic BP was independent of the difference in body mass index [16.8 $\mathrm{mmHg}(7.2-26.4 \mathrm{mmHg}), p=0.001)$, the difference in diastolic BP was attenuated after adjustment for body mass [1.8 ( -3.4 to 7.1), $p=0.49]$. Stone-formers passed less urine than controls [ $-438 \mathrm{ml} / \mathrm{day}$ $(95 \% \mathrm{CI}-852$ to -25$), p=0.038]$. They had higher urinary calcium than controls $[+3.7 \mathrm{mmol} / \mathrm{day}(2.8-$ $4.6 \mathrm{mmol} / \mathrm{day}), p<0.001]$, even when expressed as ratio to creatinine [+0.20 $(0.11-0.29), p<0.001]$. Sodium excretion was positively associated with urinary calcium in both stone-formers and in controls. The slopes were comparable $(0.92 \mathrm{vs} 0.98 \mathrm{mmol} \mathrm{Ca} / 100 \mathrm{mmol} \mathrm{Na})$ so that for any level of sodium excretion (or salt intake), stone-formers had a higher calcium excretion than controls. Conclusions: In stone-formers, the BP is higher than in controls. Stone-formers excrete more calcium than controls do. In stone-formers and controls, the relationship between urinary sodium and calcium is similar. Since this relationship results from an effect of sodium on calcium, a reduction in salt intake may be a useful method of reducing urinary calcium excretion in stone-formers. However, the "relative" hypercalciuria seen in stone-formers is independent of salt intake and may well reflect an underlying genetic predisposition. Key words: blood pressure, calcium excretion, kidney stones, salt intake, urolithiasis.

\section{INTRODUCTION}

High blood pressure is associated with abnormalities of calcium metabolism. Examples are the higher urinary calcium that is seen in hypertensives for a given sodium intake and the associated secondary hyperparathyroidism (see [1] for review). The direct relationship between urinary calcium and blood pressure has been reported in animal experimental hypertension, in children in the upper quarter of the blood pressure distribution for their age and in normotensive children of hypertensive parents [1]. In population studies, hypertension is associated with a higher prevalence of kidney stones [2,3]. The results of prospective studies, however, whilst confirming the association, shed little light on the sequence of event [4-7]. Although several case-control studies comparing hypertensives with normotensives have consistently shown that hypertensives are more likely to have renal stones, studies comparing stone-formers with controls obtained from the general population are few. The mechanisms underlying the association between high blood pressure and alterations of calcium metabolism are as yet unknown. Two main hypotheses have been put forward [1]. The "renal calcium leak" hypothesis postulates a widespread abnormality of transmembrane calcium transport, whilst the "central blood volume" hypothesis suggests the expansion of central blood volume seen in hypertension as the pathophysiological link. Either hypothesis would explain the calcium abnormalities in hypertension.

One of the major determinants of urinary calcium excretion is salt intake or urinary sodium excretion (see [1] for review), and it has been estimated that a dietary increase of $100 \mathrm{mmol}$ of sodium (approximately $6 \mathrm{~g}$ of salt) produces an increase in urinary calcium of $1 \mathrm{mmol}$ [8-10]. A high salt intake, therefore, by increasing urinary 
Table I. Characteristics of the stone-formers

\begin{tabular}{|c|c|c|c|c|c|c|c|c|c|}
\hline No. & Sex & Ethnic group & Age & Recurrence & Intervention & Stone composition & IVU & X-ray & $\mathrm{U} / \mathrm{S}$ \\
\hline 1 & $\mathrm{~F}$ & Black & 58 & $\checkmark$ & & & $\checkmark$ & & \\
\hline 2 & M & Black & 53 & $\checkmark$ & Ureteric stent & $\mathrm{Ca}-\mathrm{Ph}-\mathrm{Ox}$ & $\checkmark$ & $\checkmark$ & \\
\hline 3 & M & S Asian & 65 & $\checkmark$ & & & & $\checkmark$ & $\checkmark$ \\
\hline 4 & M & S Asian & 36 & $\checkmark$ & ESWL & $\mathrm{Ca}-\mathrm{Ph}-\mathrm{Ox}$ & $\checkmark$ & $\checkmark$ & \\
\hline 5 & M & S Asian & 62 & & ESWL & & $\checkmark$ & & \\
\hline 6 & $\mathrm{~F}$ & White & 26 & $\checkmark$ & ESWL & & $\checkmark$ & $\checkmark$ & $\checkmark$ \\
\hline 7 & $\mathrm{~F}$ & White & 27 & $\checkmark$ & & & & $\checkmark$ & $\checkmark$ \\
\hline 8 & $\mathrm{~F}$ & White & 34 & $\checkmark$ & ESWL & $\mathrm{Ca}-\mathrm{Ph}-\mathrm{Ox}$ & & $\checkmark$ & \\
\hline 9 & $\mathrm{~F}$ & White & 42 & & & & & $\checkmark$ & \\
\hline 10 & $\mathrm{~F}$ & White & 44 & & ESWL & & $\checkmark$ & $\checkmark$ & $\checkmark$ \\
\hline 11 & $\mathrm{~F}$ & White & 49 & & & & & & $\checkmark$ \\
\hline 12 & $\mathrm{~F}$ & White & 49 & $\checkmark$ & ESWL & & $\checkmark$ & $\checkmark$ & $\checkmark$ \\
\hline 13 & $\mathrm{~F}$ & White & 49 & $\checkmark$ & PCNL & $\mathrm{Ca}-\mathrm{Ph}-\mathrm{Ox}$ & $\checkmark$ & $\checkmark$ & $\checkmark$ \\
\hline 14 & $\mathrm{~F}$ & White & 52 & $\checkmark$ & & & & & $\checkmark$ \\
\hline 15 & $\mathrm{~F}$ & White & 54 & & ESWL & & & $\checkmark$ & $\checkmark$ \\
\hline 16 & $\mathrm{~F}$ & White & 64 & $\checkmark$ & ESWL & & $\checkmark$ & $\checkmark$ & \\
\hline 17 & $\mathrm{~F}$ & White & 64 & & ESWL & & & $\checkmark$ & \\
\hline 18 & M & White & 29 & $\checkmark$ & & & & & $\checkmark$ \\
\hline 19 & M & White & 33 & $\sqrt{ }$ & & & & $\checkmark$ & $\checkmark$ \\
\hline 20 & M & White & 39 & $\checkmark$ & & & $\checkmark$ & $\checkmark$ & \\
\hline 21 & M & White & 41 & $\checkmark$ & ESWL & & $\checkmark$ & $\checkmark$ & $\checkmark$ \\
\hline 22 & M & White & 42 & $\checkmark$ & ESWL & $\mathrm{Ca}-\mathrm{Ox}$ & $\checkmark$ & $\checkmark$ & $\checkmark$ \\
\hline 23 & M & White & 44 & $\checkmark$ & Ureterolithotomy & $\mathrm{Ca}-\mathrm{Ph}-\mathrm{Ox}$ & $\checkmark$ & $\checkmark$ & $\checkmark$ \\
\hline 24 & M & White & 44 & $\checkmark$ & & $\mathrm{Ca}-\mathrm{Ph}-\mathrm{Ox}$ & $\checkmark$ & $\checkmark$ & \\
\hline 25 & M & White & 45 & $\checkmark$ & & & & $\checkmark$ & \\
\hline 26 & M & White & 46 & $\checkmark$ & Ureterolithotomy & & $\checkmark$ & $\checkmark$ & $\checkmark$ \\
\hline 27 & M & White & 48 & $\checkmark$ & & & $\checkmark$ & $\checkmark$ & $\checkmark$ \\
\hline 28 & M & White & 48 & & & & $\checkmark$ & $\checkmark$ & $\checkmark$ \\
\hline 29 & M & White & 51 & $\checkmark$ & ESWL & & $\checkmark$ & $\checkmark$ & \\
\hline 30 & M & White & 52 & $\checkmark$ & & & & $\checkmark$ & $\checkmark$ \\
\hline 31 & M & White & 55 & $\checkmark$ & Ureteric stent & & $\checkmark$ & $\checkmark$ & \\
\hline 32 & M & White & 55 & $\checkmark$ & & $\mathrm{Ca}-\mathrm{Ph}$ & $\checkmark$ & $\checkmark$ & $\checkmark$ \\
\hline 33 & M & White & 64 & $\checkmark$ & ESWL & $\mathrm{Ca}-\mathrm{Ox}$ & $\checkmark$ & $\checkmark$ & $\checkmark$ \\
\hline 34 & M & White & 65 & $\checkmark$ & ESWL and Nephrectomy & & & & $\checkmark$ \\
\hline 35 & M & White & 67 & $\checkmark$ & Ureteric stent & & $\checkmark$ & $\checkmark$ & \\
\hline 36 & M & White & 70 & $\checkmark$ & ESWL and PCNICa-Ox & & $\checkmark$ & $\checkmark$ & \\
\hline
\end{tabular}

ESWL, extracorporeal shock-wave lithotripsy; PCNL, percutaneous nephrolithotomy; Ca, calcium; Ph, phosphate; Ox, oxalate.

calcium excretion, may facilitate the formation of calcium stones [9]. The objectives of the present study are: (i) to determine whether stone-formers have higher blood pressure than controls drawn from the general population and matched for age, sex and ethnic origin and (ii) to compare the relationship between urinary sodium and calcium in the two groups.

\section{METHODS}

\section{Selection of cases}

Thirty-six patients seen in the Medical Renal Stone Clinic at St George's Hospital between 1999 and 2001 were included in the analysis. They all had a diagnosis of kidney or ureteric stones made by intra-venous ureteropyelography (IVU), abdominal X-ray or renal ultra-sound (U/S) (Table I). Twenty-nine of them $(81 \%)$ had had one or more recurrences and $21(58 \%)$ had undergone surgical procedures for the removal of the calculi (Table I). All contained calcium either as calcium oxalate or calcium phosphate, or a combination of the two (Table I). Parathyroid overactivity was excluded by measurements of serum immunoreactive parathyroid hormone (i-PTH). 25-Hydroxy vitamin D levels (vit D) were within the normal range in all the stone-formers. Twenty-three were men, and the majority were white (Table I). Mean ( \pm standard deviation, SD) age was $49.0 \pm 11.7$ years (range 27-70 years). Fourteen (39\%) gave a history of urinary tract calculi in first-degree relatives.

\section{Selection of controls}

Controls were selected from a population database of individuals participating in the Wandsworth Heart \& Stroke Study, a cross-sectional survey of men and women of different ethnic groups living in Wandsworth (South 
Table II. Comparisons of stone-formers and population controls

\begin{tabular}{|c|c|c|c|c|}
\hline & $\begin{array}{l}\text { Renal stones } \\
(n=36)\end{array}$ & $\begin{array}{l}\text { Population controls } \\
(n=108)\end{array}$ & $\begin{array}{l}\text { Difference } \\
(95 \% \mathrm{CI})\end{array}$ & $p$ \\
\hline Body mass index $\left(\mathrm{kg} / \mathrm{m}^{2}\right)$ & $30.4(5.5)$ & $25.0(4.1)$ & $5.3(3.1-7.5)$ & $<0.001$ \\
\hline Systolic blood pressure (mmHg) & $142.4(20.0)$ & $124.4(17.2)$ & $18.0(11.2-24.8)$ & $<0.001$ \\
\hline Diastolic blood pressure $(\mathrm{mmHg})$ & $84.0(10.5)$ & $79.7(10.0)$ & $4.3(0.5-8.2)$ & 0.028 \\
\hline Anti-hypertensive treatment (n) & 19 & 0 & & \\
\hline \multicolumn{5}{|l|}{ Serum } \\
\hline Sodium (mM) & $138.7(2.1)$ & $139.4(2.7)$ & $-0.6(-1.6$ to 0.3$)$ & 0.193 \\
\hline Potassium (mM) & $4.2(0.4)$ & $4.2(0.2)$ & $0(-0.1$ to -0.1$)$ & 0.461 \\
\hline Creatinine $(\mu \mathrm{M})$ & $87.5(14.4)$ & $86.3(13.0)$ & $1.1(-4.0$ to 6.2$)$ & 0.657 \\
\hline Uric acid $(\mu \mathrm{M})$ & $311(82)$ & $286(85)$ & $25(-19$ to 69$)$ & 0.264 \\
\hline Glucose (mM) & $5.54(1.13)$ & $5.20(1.60)$ & $0.37(-0.25$ to 0.98$)$ & 0.240 \\
\hline \multicolumn{5}{|l|}{ Urine } \\
\hline Volume (ml/day) & $2139(812)$ & $2578(1164)$ & $-438(-852$ to -25$)$ & 0.038 \\
\hline Sodium (mmol/day) & $156.0(69.1)$ & $165.0(72.0)$ & $-8.7(-35.7$ to 18.3$)$ & 0.526 \\
\hline Potassium (mmol/day) & $82.5(31.0)$ & $70.6(24.4)$ & $11.9(2.0-22.0)$ & 0.019 \\
\hline Creatinine (mmol/day) & $14.7(4.2)$ & $12.6(4.2)$ & $2.1(0.5-3.8)$ & 0.010 \\
\hline Calcium (mmol/day) & $8.0(3.0)$ & $4.3(2.2)$ & $3.7(2.8-4.6)$ & $<0.001$ \\
\hline Calcium/creatinine & $0.57(0.24)$ & $0.37(0.23)$ & $0.20(0.11-0.29)$ & $<0.001$ \\
\hline
\end{tabular}

Results are mean (SD), differences (95\% CI).

London) [10-12]. After exclusion of people with a past history of myocardial infarction, stroke and renal stones, three controls were selected for each case, matching for gender, ethnic origin and age group. The 108 controls so obtained had a mean age of $49.6 \pm 6.8$ years (range 39-61 years).

\section{Procedures}

Patients and controls underwent measurements using standard methods [12]. Height (without shoes) was measured to the nearest centimetre using a wall-mounted ruler. Weight (light clothing and no shoes) was measured to the nearest $0.1 \mathrm{~kg}$ using electronic scales. The body mass index (BMI) was calculated as weight $/$ height $^{2}(\mathrm{~kg} /$ $\mathrm{m}^{2}$ ). After the subjects had been resting for 5-10 min in the supine position, systolic and diastolic blood pressures were taken three times 2 min apart using an automatic sphygmomanometer and an appropriate cuff size. The average of the last two readings was used for the analysis.

A venous blood sample was taken for measurement of serum electrolytes, creatinine, glucose and uric acid in both patients and controls [12]. In the patients, i-PTH and vit $\mathrm{D}$ were also measured. Both patients and controls were also asked to collect a 24 -h urine sample. They were given written instructions as to how to undertake the collection and supplied with a 2.5-1 plastic container. Complete urine collections were either returned by the participants or collected from their home. Time and volume of collections were carefully recorded. Sodium, potassium, creatinine and calcium were measured by standard methods $[10,12]$. The procedures were approved by the local ethics committee.

\section{Statistical analysis}

Comparisons of means between groups were carried out using unpaired $t$-tests. Analysis of covariance was used to adjust for confounders. Regression analysis was used to assess the degree of change of urinary calcium excretion over sodium excretion. Slopes were compared by an interaction test. The analysis was carried out using SPSS v10.0.

\section{RESULTS}

Patients with renal stones were significantly heavier than age-, sex- and race-matched population controls (Table II). Furthermore, they had significantly higher blood pressures than controls. Whilst the difference in systolic blood pressure was independent of the difference in body mass index [adjusted systolic blood pressure: 141.9 vs $125.1 \mathrm{mmHg}$; difference $16.8 \mathrm{mmHg}(7.2-26.4 \mathrm{mmHg})$; $p=0.001]$, the difference in diastolic blood pressure was attenuated after adjustment for body mass [adjusted diastolic blood pressure: 82.1 vs $80.2 \mathrm{mmHg}$; difference $1.8 \mathrm{mmHg}(-3.4$ to $7.1 \mathrm{mmHg}) ; p=0.49$ ]. The two groups had comparable electrolytes, glucose, uric acid and creatinine (Table II). Patients with renal stones passed less urine than the controls $(-438 \mathrm{ml} /$ day; $95 \%$ confidence interval, CI -852 to $-25 \mathrm{ml} /$ day) (Table II). Whilst both urinary sodium and potassium excretion were comparable, patients with renal stones had significantly higher urinary calcium excretion than the controls 
Stone-formers $(\mathrm{n}=36)$

Slope: $0.92 \mathrm{mmol} \mathrm{Ca} / 100 \mathrm{mmol} \mathrm{Na}$

$95 \% \mathrm{Cl}:-0.60,2.40$

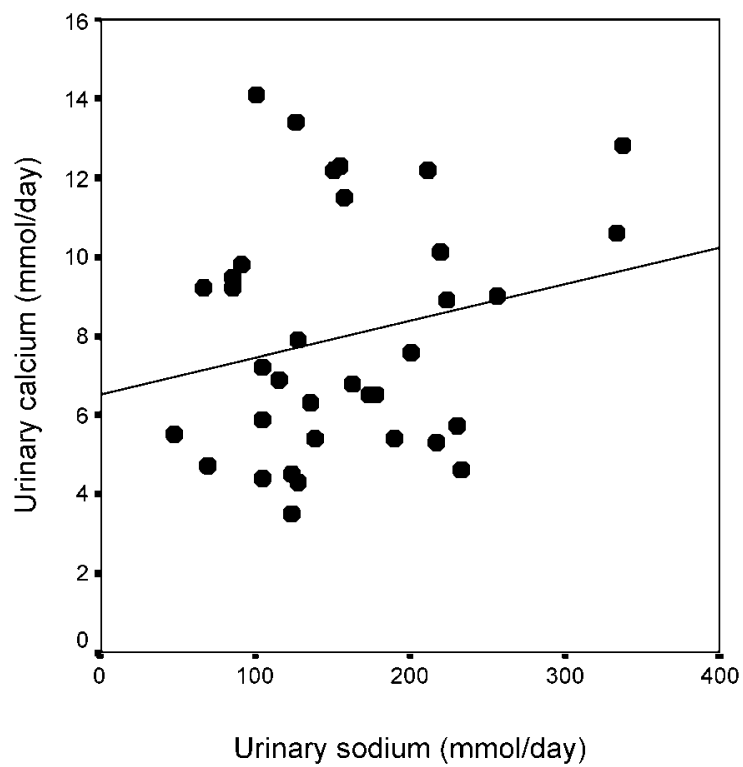

Population controls $(n=108)$

Slope: $0.98 \mathrm{mmol} \mathrm{Ca} / 100 \mathrm{mmol} \mathrm{Na}$ $95 \% \mathrm{Cl}: 0.40,1.50$

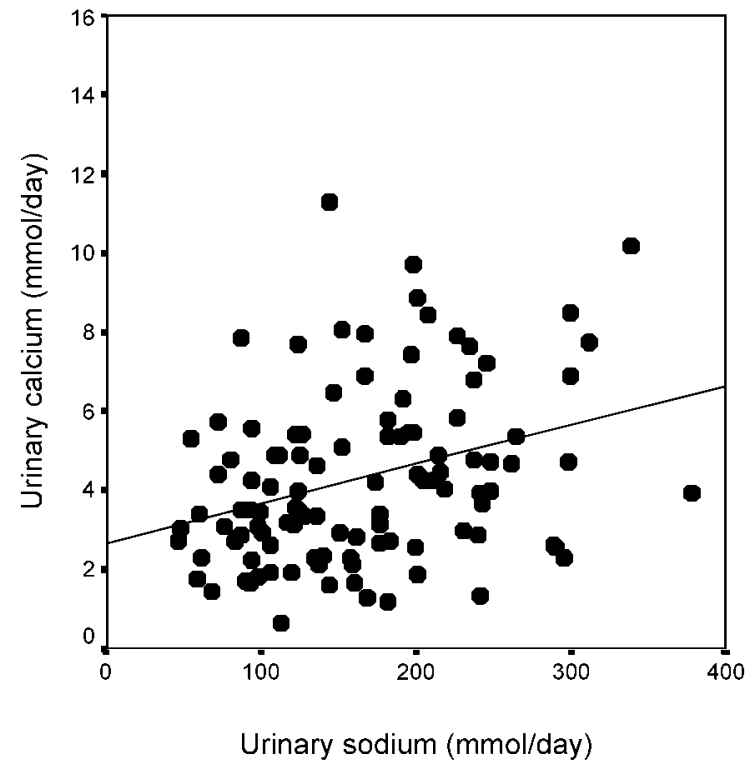

Fig. 1. Relationships between urinary sodium and calcium excretions in stone formers (left) and population controls (right).

(+3.7 mmol/day; $2.8-4.6 \mathrm{mmol} /$ day), even when adjusted for differences in urinary creatinine excretion $(+0.20$; 0.11-0.29). Urinary sodium excretion was positively associated with urinary calcium excretion in both patients with renal stones $(r=0.22)$ and in the controls $(r=0.32)$, even when expressed as creatinine ratio $(r=0.21$ and $r=0.28$, respectively) (Fig. 1). Furthermore, the slopes of the regression lines were comparable in patients and controls; indeed, it can be seen that in both groups a change in urinary sodium (salt intake) of $100 \mathrm{mmol}$ is accompanied by a change in urinary calcium of almost $1 \mathrm{mmol}$. For any given level of sodium excretion (or salt intake), however, patients with renal stones have a higher urinary calcium excretion compared to age-, sex- and race-matched population controls [intercept at urinary sodium excretion $=0$ : cases $6.5(95 \%$ CI $4.0-9.1)$ vs controls 2.7 (1.7-3.7)]. Amongst the cases, 15 (42\%) had undergone extracorporeal shock wave lithotripsy
(ESWL). They did not differ from those who did not (Table III).

\section{DISCUSSION}

Our study shows that in patients with known urinary tract calculi, the blood pressure is higher than in age-, sex- and race-matched controls drawn from the same population from which the cases were obtained. The stone-formers also had a much higher urinary calcium excretion (almost double) than controls. The study suggests that stoneformers are more likely to have hypertension than the general population and that the causal link between hypertension and urolithiasis may be a high urinary calcium excretion.

The study suggests that in stone-formers and controls the relationship between urinary sodium and urinary calcium is similar. Indeed, the slopes of the two

Table III. Comparisons of stone-formers who had extracorporeal shock wave lithotripsy (ESWL) and those who did not

\begin{tabular}{|c|c|c|c|c|}
\hline & $\begin{array}{l}\text { ESWL - Yes } \\
(n=15)\end{array}$ & $\begin{array}{l}\text { ESWL - No } \\
(n=21)\end{array}$ & $\begin{array}{l}\text { Difference } \\
(95 \% \mathrm{CI})\end{array}$ & $p$ \\
\hline Age (years) & $51.1(13.5)$ & $47.6(10.2)$ & $3.4(-4.6$ to 11.5$)$ & 0.39 \\
\hline Systolic blood pressure (mmHg) & $140.3(16.8)$ & $143.8(22.3)$ & $-3.5(-17.4$ to 10.4$)$ & 0.61 \\
\hline Diastolic blood pressure (mmHg) & $79.1(7.5)$ & $87.6(11.0)$ & $-8.4(-15.1$ to -1.7$)$ & 0.015 \\
\hline Urinary sodium (mmol/day) & $149(76)$ & $161(65)$ & $-12(-60$ to 36$)$ & 0.61 \\
\hline Urinary calcium (mmol/day) & $7.7(3.1)$ & $8.2(3.0)$ & $-0.44(-2.55$ to 1.67$)$ & 0.67 \\
\hline
\end{tabular}


regression lines are almost identical. We would expect that for a 100-mmol change in urinary sodium (i.e. $\sim 6 \mathrm{~g}$ of salt intake) there would be a 1-mmol change in urinary calcium in both stone-formers and in controls. Since this relationship results from an effect of sodium on calcium [1], a reduction in salt intake is potentially a useful method for controlling hypercalciuria in stone-formers. Muldowney et al. [13] demonstrated clearly in the early 1980s how closely urinary calcium followed salt intake and urinary sodium excretion, so that the definition of "idiopathic" hypercalciuria would be meaningless without allowing for the concurrent sodium intake. More recently, clinical anecdotes have strongly supported the view that a moderate reduction in salt intake could play a very important clinical role in reducing urinary calcium excretion, blood pressure and the recurrence of kidney stones in hypertensive patients suffering from recurrent urolithiasis [14]. A significant and long-term reduction in salt intake can be achieved in patients, and contrasts with the difficulty of reducing calcium intake which is much more commonly advised for this condition [15], without much evidence that it has a major effect on calcium excretion. Indeed there is convincing evidence that it can increase recurrence due to the increase in oxalate absorption [16, 17]. Finally, a recent randomized trial in men has shown that unlike dietary calcium restriction a moderate reduction in dietary protein and salt (as far as it is possible in day-to-day life) reduced the recurrence of stones in patients with "idiopathic" hypercalciuria by half over 5 years [18].

The development and introduction of ESWL in the early 1980s has dramatically changed the management of upper urinary tract calculi. Concern has been expressed about possible short- and long-term consequences of ESWL on kidney structure and function. In particular, a number of uncontrolled and/or retrospective early reports suggested that ESWL might cause hypertension [19-21]. On the other hand, these postulated deleterious effects have not been confirmed by others [22-25] and two recent independent randomized controlled trials in the USA [26] and in the UK [27] have shown that there is no detectable increase in the incidence of hypertension following ESWL. In our study, patients who had received ESWL did not have higher blood pressure than those who had not received it, so any difference in blood pressure between stone-formers and controls cannot be ascribed to ESWL treatment.

The "relative" hypercalciuria seen in stone-formers compared to population controls appears to be independent of salt intake and may well reflect an underlying renal calcium leak. We were surprised by the number of patients who had family members with stones. Genetic influences may be much more important than previously thought, and gaining an understanding of the underlying mechanisms may help to reveal the causes of the so-called "idiopathic" hypercalciuria of stone-formers $[28,29]$.

\section{ACKNOWLEDGMENTS}

The paper was presented, in part, at the 9th European Meeting on Cardionephrology, Assisi, April 11-13, 2002 and at the 13th Annual Symposium of the London Hypertension Society, London, May 20, 2002. FPC is a member of the St George's Cardiovascular Research Group.

\section{REFERENCES}

1. Cappuccio FP, Kalaitzidis RG, Duneclift S, Eastwood JB. Unravelling the links between calcium excretion, salt intake, hypertension, kidney stones and bone metabolism. J Nephrol 2000; 13: 169-77.

2. Cappuccio FP, Strazzullo P, Mancini M. Kidney stones and hypertension: population based study of an independent clinical association. Br Med J 1990; 300: 1234-6.

3. Borghi L, Meschi T, Guerra A, et al. Essential arterial hypertension and stone disease. Kidney Int 1999; 55: 2397 406.

4. Madore F, Stampfer MJ, Rimm EB, Curhan GC. Nephrolithiasis and risk of hypertension. Am J Hypertens 1998; 11: 46-53.

5. Madore F, Stampfer MJ, Willett WC, Speizer FE, Curhan GC. Nephrolithiasis and risk of hypertension in women. Am J Kidney Dis 1998; 32: 802-7.

6. Cappuccio FP, Siani A, Barba G, et al. A prospective study of hypertension and the incidence of kidney stones in men. $\mathrm{J}$ Hypertens 1999; 17: 1017-22.

7. Strazzullo P, Barba G, Vuotto P, et al. Past history of nephrolithiasis and incidence of hypertension in men: a reappraisal based on the results of the Olivetti Prospective Heart Study. Nephrol Dial Transplant 2001; 16: 2232-5.

8. Cirillo M, Ciacci C, Laurenzi M, Mellone M, Mazzacca G, De Santo NG. Salt intake, urinary sodium and hypercalciuria. Miner Electr Metab 1997; 23: 265-8.

9. Cirillo M, Laurenzi M, Panarelli W, Stamler J. Urinary sodium to potassium ratio and urinary stone disease. Kidney Int 1994; 46: 1133-9.

10. Blackwood AM, Sagnella GA, Cook DG, Cappuccio FP. Urinary calcium excretion, sodium intake and blood pressure in a multi-ethnic population: results of the Wandsworth Heart and Stroke Study. J Hum Hypertens 2001; 15: 229-37.

11. Cappuccio FP, Cook DG, Atkinson RW, Strazzullo P. Prevalence, detection, and management of cardiovascular risk factors in different ethnic groups in south London. Heart 1997; 78: 555-63.

12. Cappuccio FP, Cook DG, Atkinson RW, Wicks PD. The Wandsworth Heart and Stroke Study. A population-based survey of cardiovascular risk factors in different ethnic groups. Methods and baseline findings. Nutr Metab Cardiovasc Dis 1998; 8: 371-85.

13. Muldowney FP, Freaney R, Moloney MF. Importance of dietary sodium in the hypercalciuria syndrome. Kidney Int 1982; 22: 292-6.

14. Saggar-Malik AK, Markandu ND, MacGregor GA, Cappuccio FP. Moderate salt restriction for the management of hypertension and hypercalciuria. J Hum Hypertens 1996; 10: 811-13. 
15. Coe FL, Parks JH, Asplin JR. The pathogenesis and treatment of kidney stones. N Engl J Med 1992; 327: 1141-52.

16. Curhan GC, Willett WC, Rimm EB, Stampfer MJ. A prospective study of dietary calcium and other nutrients and the risk of symptomatic kidney stones. N Engl J Med 1993; 328: 833-8.

17. Curhan GC, Willett WC, Speizer FE, Speigelman D, Stampfer MJ. Comparison of dietary calcium with supplemental calcium and other nutrients as factors affecting the risk for kidney stones in women. Ann Intern Med 1997; 126: 497-504.

18. Borghi L, Schianchi T, Meschi T, Guerra A, Allegri F, Maggiore U, Novarini A. Comparison of two diets for the prevention of recurrent stones in idiopathic hypercalciuria. N Engl J Med 2002; 346: 77-84.

19. Lingeman JE, Kulb TB. Hypertension following ESWL. J Urol 1987; 137: 142A.

20. Williams CM, Kaude JV, Newman RC, Peterson JC, Thomas WC. Extracorporeal shockwave lithotripsy: longterm complications. Am J Roentgenol 1988; 150: 311-15.

21. Montgomery BS, Cole RS, Palfrey EL, Shuttleworth KE. Does ESWL cause hypertension? Br J Urol 1989; 64: 56771.

22. Germinale F, Puppo P, Bottino P, Caviglia C, Ricciotti G. ESWL and hypertension: no evidence for causal relationship. J Urol 1989; 141: 288A.

23. Sandlow JI, Winfield HN, Loening SA. Blood pressure changes related to ESWL. J Urol 1989: 290A.

24. Yokoyama M, Shoji F, Yanagizawa R. Blood pressure changes following ESWL for urolithiasis. J Urol 1992: 553-8.
25. Vaughan ED, Tobin JN, Alderman R. Extracorporeal shock wave monotherapy does not cause renal dysfunction elevated blood pressure. J Urol 1996; 155: 539A.

26. Jewett MAS, Bombardier C, Logan AG, et al. A randomized controlled trial to assess the incidence of newe onset hypertension in patients after shock wave lithotripsy for asymptomatic renal calculi. J Urol 1998; 160: 1241-3.

27. Elves AWS, Tilling K, Menezes P, Wills M, Rao PN, Feneley RCL. Early observations of the effect of extracorporeal shockwave lithotripsy on blood pressure: a prospective randomized control clinical trial. $\mathrm{Br} \mathrm{J}$ Urol 2000; 85: 611-15.

28. Unwin R, Wrong O, Cohen E, Tanner M, Thakker R. Unravelling of the molecular mechanisms of kidney stones. Lancet 1996; 348: 1561-5.

29. Vezzoli G, Tanini A, Ferrucci L, et al. Influence of calciumsensing receptor gene on urinary calcium excretion in stoneforming patients. J Am Soc Nephrol 2002; 13: 2517-523.

Submitted November 8, 2002; accepted January 13, 2003

\section{Address for correspondence:}

Prof. F. P. Cappuccio

Department of Community Health Sciences

St George's Hospital Medical School

Cranmer Terrace

London SW17 ORE

UK

Tel: +44208725 3329

Fax: +442087252234

E-mail: f.cappuccio@sghms.ac.uk 